\title{
Ciência, tecnologia, parlamento e os diálogos com os cidadãos
}

\author{
Science, technology, parliament, and \\ dialoguing with citizens
}

\section{Luisa Massarani}

Coordenadora do Centro de Estudos do Museu da Vida Casa de Oswaldo Cruz/Fiocruz Av. Brasil 4365, Manguinhos 21045-900 Rio de Janeiro RJ - Brasil

lumassa@fiocruz.br
MASSARANI, L.: Ciência, tecnologia, parlamento e os diálogos com os cidadãos

História, Ciências, Saúde - Manguinhos, v. 12, n. 2, p. 469-72, maio-ago. 2005.

Este mini-dossiê discute a importância de se ampliar a participação do público não-especializado no processo decisório relacionado a temas de ciência e tecnologia que têm impacto significativo na sociedade. Trata-se de uma coletânea de textos que inclui a experiência da Dinamarca - que se tornou modelo internacional de realização de mecanismos participativos na área -, do Canadá, da Argentina e do Chile, além de uma contribuição do Reino Unido com algumas reflexões sobre o tema. Esperamos que seja o ponto de partida para uma discussão mais ampla sobre o tema e que gere frutos para o aumento da participação pública em temas de ciência e tecnologia no Brasil e em outros países da América Latina.

PALAVRAS-CHAVE: participação pública em C\&T; modelos deliberativos em C\&T; América Latina.

MASSARANI, L.: Science, technology, parliament, and dialoguing with citizens

História, Ciências, Saúde - Manguinhos, v. 12, n. 2, p. 469-72, May-Aug. 2005.

This mini-dossier discusses the importance of expanding the nonspecialized public's participation in the decision-making process surrounding those issues in science and technology that have a significant impact on society. This collection of texts includes experiences from Denmark (which now serves as an international model in participative mechanisms), Canada, Argentina, and Chile, along with a contribution from the United Kingdom with some thoughts on the topic. ${ }^{1}$ We hope it will be the starting point for a broader discussion and that it will foster increased public participation in science and technology topics in Brazil and other Latin American nations.

KEYWORDS: public participation in SET; deliberative models in SET; Latin America. 
A ciência e a tecnologia têm, cada vez mais, aplicações que afetam de forma significativa a sociedade. Pesquisas com células-tronco embrionárias, plantios e alimentos geneticamente modificados e produtos gerados por meio de nanotecnologia são apenas alguns exemplos que vêm gerando controvérsias e acirrados debates tanto na comunidade científica como fora do âmbito acadêmico.

No entanto, são comuns - em particular na América Latina - os episódios em que, em vez de se criarem estratégias para trazer ao debate, de forma mais democrática, temas relacionados à ciência e à tecnologia, a sociedade tem sido excluída do processo decisório em questões que têm impacto na vida cotidiana das pessoas.

Exemplo disto é o episódio recente da introdução de alimentos e plantações geneticamente modificados no Brasil, tema que vem causando controvérsias desde 1998, acirradas em 2003. Embora o cultivo e a comercialização de produtos geneticamente modificados fossem na ocasião proibidos por lei no Brasil, em fevereiro de 2003 descobriu-se que grande proporção da soja plantada no Sul do país era transgênica. Pouco após anunciar que a proibição seria mantida, o governo decidiu permitir a venda para consumo animal e humano, sob o argumento de que se tratava de um problema social e econômico importante, tendo em vista que envolvia milhões de toneladas de soja e grande número de pequenos agricultores. A decisão foi tomada aproximadamente dois meses após serem anunciados os resultados de uma pesquisa de opinião pública que reiterava dados de estudo similar feito no ano anterior: cerca de $70 \%$ dos brasileiros preferem comer alimentos não transgênicos; cerca de $90 \%$ dos entrevistados afirmam que, se tem de haver alimentos transgênicos vendidos nos supermercados, que sejam rotulados.

O tema dos transgênicos - longe de ser apenas uma opção alimentícia ou uma questão restrita ao âmbito acadêmico - tem impacto importante em aspectos variados do país. Para ilustrar isto, basta lembrar seu caráter econômico: por um lado, sementes transgênicas são recusadas por alguns países, em particular na Europa; por outro, como alegam os defensores delas, há expectativas de que gerariam plantações muito mais produtivas e resistentes a pragas. O Brasil é um dos maiores exportadores de produtos agrícolas do mundo e a agricultura é responsável por 13\% do produto interno bruto brasileiro, com papel significativo na balança comercial do país. Ressalte-se, ainda, que os transgênicos passaram a ser regulamentados pela controversa lei de biossegurança, que inclui também a pesquisa com células-tronco de embriões e que foi aprovada em março de 2005 sem que tenha havido um processo de discussão e participação amplo do ponto de vista da sociedade, embora vários setores determinados, muitos dos quais com perspectivas corporativas estreitas, se fizessem presentes no processo. 
Vale lembrar que a introdução de inovações científicas e tecnológicas, bem como de equipamentos e comportamentos, sem um engajamento e processos adaptativos apropriados da sociedade pode levar, em situações extremas, a revoltas populares, como ocorreu no Brasil com a introdução do sistema métrico decimal (Revolta dos Quebra-Quilo), na segunda metade do século XIX, e com as campanhas de vacinação (Revolta da Vacina), no início do século XX.

No cenário internacional, países distintos como Dinamarca, Canadá, Reino Unido, Nova Zelândia, Japão e França, entre outros, têm usado, em maior ou menor grau, mecanismos de participação pública, que incluem conferências de consenso, júris de cidadãos, consultas públicas e referendos. Essa tarefa é mais desafiadora em nosso continente, tendo em vista a tradição de autoritarismo e a visão excludente predominante, que também afeta alguns membros da comunidade científica - estes consideram ser necessária uma formação científica formal de alto nível para que se possa opinar e influenciar nas grandes decisões políticas que envolvem ciência e tecnologia.

Ainda assim, nos últimos anos, algumas iniciativas para incrementar a participação pública em temas de ciência e tecnologia têm despontado em nosso continente, ainda que de forma mais pontual e por vezes sem efeito prático. Exemplo disso é um artigo na legislação do Rio de Janeiro, requerendo que qualquer decisão em ciência e tecnologia que represente um impacto mais substancial na sociedade - a exemplo da construção de uma hidrelétrica ou usina nuclear, por exemplo - só pode ser tomada após consulta à população. Tal artigo, no entanto, nunca foi regulamentado. Porém, existem bons exemplos de iniciativas da sociedade civil, envolvendo metodologias participativas: conferências de consenso foram realizadas na Argentina e no Chile, e serão detalhadas mais adiante neste mini-dossiê.

Partindo do pressuposto de que a sociedade pode e deve participar de processos decisórios na área de ciência e tecnologia que podem afetar profundamente seu futuro e a vida dos cidadãos, e com objetivo de trazer o tema à discussão, o Centro de Estudos do Museu da Vida da Casa de Oswaldo Cruz/Fiocruz e a revista História, Ciências, Saúde - Manguinhos prepararam este conjunto de depoimentos de pessoas que vêm se preocupando com a participação pública em ciência e tecnologia e estão - ou estiveram - envolvidos com iniciativas práticas que buscam aproximar a sociedade dos processos decisórios.

O mini-dossiê se abre com uma entrevista concedida em parceria pelo biólogo Lars Klüver e pela especialista em comunicação Edna F. Einsiedel, dois nomes de destaque nessa área. Klüver é diretor do Conselho Dinamarquês de Tecnologia (Teknologirådet), 
que se tornou paradigma internacional de realização de modelos participativos em temas de ciência e tecnologia. Einsiedel tem envolvimento direto na organização de conferências de consenso no Canadá e focaliza suas pesquisas nos modelos deliberativos.

Em seguida, publicamos uma transcrição adaptada de uma palestra proferida no Rio de Janeiro pelo sociólogo Tom Shakespeare, do Reino Unido.

Cruzamos os mares e chegamos a duas experiências precursoras em nosso continente, realizadas na Argentina, em 2000, e no Chile, em 2003, discutidas pelo engenheiro Ricardo A. Ferraro; pela socióloga Adriana Bacciadonne e pelo especialista em biotecnologia Alberto Díaz (experiência Argentina); e pelo médico Alberto Pellegrini Filho (experiência chilena). A contribuição da Argentina permite-nos o acesso a trechos do relatório final de uma das conferências de consenso realizadas naquele país. Já o artigo sobre a experiência chilena discute como foi o processo de adaptação do mecanismo participativo desenvolvido na Dinamarca para o contexto latino-americano.

O mini-dossiê é, por certo, não-exaustivo. Mas esperamos que seja o ponto de partida para uma discussão mais ampla e que gere frutos no incremento da participação pública em temas de ciência e tecnologia, no Brasil e em outros países da América Latina.

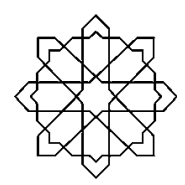

